OPEN ACCESS

Check for updates

\section{The prevalence of loneliness across 113 countries: systematic review and meta-analysis}

\author{
Daniel L Surkalim, ${ }^{1,2}$ Mengyun Luo, ${ }^{1,2}$ Robert Eres, ${ }^{3,4}$ Klaus Gebel, ${ }^{5}$ Joseph van Buskirk, ${ }^{1}$ \\ Adrian Bauman,, ${ }^{1,2}$ Ding Ding ${ }^{1,2}$
}

Faculty of Medicine and Health,

The University of Sydney,

Camperdown, NSW, Australia

${ }^{2}$ Charles Perkins Centre (D17)

The University of Sydney,

Australia

${ }^{3}$ Neurodisability and

Rehabilitation, Murdoch

Children's Research Institute,

Royal Children's Hospital,

Parkville, VIC, Australia

${ }^{4}$ Department of Paediatrics,

The University of Melbourne,

Parkville, VIC, Australia

${ }^{5}$ Australian Centre for Public and Population Health Research,

School of Public Health,

Faculty of Health, University of

Technology Sydney, Ultimo, NSW,

Australia

Correspondence to: D Ding

melody.ding@sydney.edu.au

(ORCID 0000-0001-9850-9224)

Additional material is published online only. To view please visit

the journal online.

Cite this as: $B M J$ 2022;376:e067068

http://dx.doi.org/10.1136/

bmj-2021-067068

Accepted: 15 December 2021
${ }^{1}$ Sydney School of Public Health,

Camperdown, NSW, 2006,

\section{ABSTRACT}

OBJECTIVES

To identify data availability, gaps, and patterns for population level prevalence of loneliness globally, to summarise prevalence estimates within World Health Organization regions when feasible through meta-analysis, and to examine temporal trends of loneliness in countries where data exist.

\section{DESIGN}

Systematic review and meta-analysis.

\section{DATA SOURCES}

Embase, Medline, PsycINFO, and Scopus for peer reviewed literature, and Google Scholar and Open Grey for grey literature, supplemented by backward reference searching (to 1 September 2021)

\section{ELIGIBILITY CRITERIA FOR SELECTING STUDIES}

Observational studies based on nationally representative samples $(n \geq 292)$, validated instruments, and prevalence data for 2000-19. Two researchers independently extracted data and assessed the risk of bias using the Joanna Briggs Institute checklist. Random effects meta-analysis was conducted in the subset of studies with relatively homogeneous research methods by measurement instrument, age group, and WHO region.

RESULTS

Prevalence data were available for 113 countries or territories, according to official WHO nomenclature for regions, from 57 studies. Data were available for adolescents (12-17 years) in 77 countries or territories, young adults (18-29 years) in 30 countries, middle aged adults ( $30-59$ years) in 32 countries, and older adults ( $\geq 60$ years) in 40 countries. Data for all age groups except adolescents were lacking outside of Europe. Overall, 212 estimates for 106 countries

\section{WHAT IS ALREADY KNOWN ON THIS TOPIC}

Increasing evidence suggests that loneliness at a problematic level has serious health consequences

As loneliness is increasingly recognised as an important health and social problem, governments worldwide should aim to tackle this issue through policies and initiatives

It is still unclear how widespread loneliness is on a global scale

\section{WHAT THIS STUDY ADDS}

Loneliness at a problematic level is prevalent in many countries, and important data gaps exist, particularly in low and middle income countries

A geographical pattern for loneliness prevalence was found, with northern European countries consistently showing low levels

Data are insufficient to make conclusions about temporal trends of loneliness on a global scale from 24 studies were included in meta-analyses. The pooled prevalence of loneliness for adolescents ranged from $9.2 \%$ (95\% confidence interval 6.8\% to $12.4 \%)$ in South-East Asia to $14.4 \%$ (12.2\% to $17.1 \%)$ in the Eastern Mediterranean region. For adults, meta-analysis was conducted for the European region only, and a consistent geographical pattern was shown for all adult age groups. The lowest prevalence of loneliness was consistently observed in northern European countries $(2.9 \%, 1.8 \%$ to $4.5 \%$ for young adults; $2.7 \%, 2.4 \%$ to $3.0 \%$ for middle aged adults; and $5.2 \%, 4.2 \%$ to $6.5 \%$ for older adults) and the highest in eastern European countries (7.5\%, 5.9\% to $9.4 \%$ for young adults; $9.6 \%, 7.7 \%$ to $12.0 \%$ for middle aged adults; and $21.3 \%, 18.7 \%$ to $24.2 \%$ for older adults).

\section{CONCLUSION}

Problematic levels of loneliness are experienced by a substantial proportion of the population in many countries. The substantial difference in data coverage between high income countries (particularly Europe) and low and middle income countries raised an important equity issue. Evidence on the temporal trends of loneliness is insufficient. The findings of this meta-analysis are limited by data scarcity and methodological heterogeneity. Loneliness should be incorporated into general health surveillance with broader geographical and age coverage, using standardised and validated measurement tools.

\section{SYSTEMATIC REVIEW REGISTRATION} PROSPERO CRD42019131448.

\section{Introduction}

Humans thrive on meaningful social connections. Feelings of loneliness set in when a discrepancy exists between one's desired and one's actual level of social relationships. ${ }^{1}$ Loneliness is a negative, subjective experience $^{2}$ closely linked to the quality of social connections. ${ }^{3}$ Loneliness is similar to, but distinct from, social isolation, which is defined as a lack of social contacts, and being alone, characterised as being physically removed from social connections. ${ }^{4}$ Transient loneliness is a common experience, ${ }^{5}$ but chronic or severe loneliness pose threats to health and wellbeing.

Growing evidence has linked loneliness to various adverse health outcomes. Loneliness is associated with unfavourable cardiovascular health indicators, such as increased activation of the hypothalamicpituitary-adrenal axis, ${ }^{6}$ high blood pressure, increased

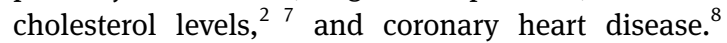
Loneliness is associated with sleep disturbance ${ }^{9}$ and increased risk of mild cognitive impairment and 
dementia. ${ }^{10}$ Loneliness may also be detrimental to behavioural, mental, and social health throughout the lifespan, ${ }^{2}$ influencing outcomes such as substance misuse, suicidal ideation, ${ }^{11}$ anxiety, depression, ${ }^{12}$ and poor subjective wellbeing. ${ }^{7}$ According to a 2015 metaanalysis, people with chronic loneliness had a $26 \%$ increased risk of mortality. ${ }^{13}$ This increased risk is comparable to established risk factors such as physical inactivity ${ }^{14}$ and grade 1 obesity. ${ }^{15}$

Culture affects levels of loneliness. ${ }^{16}$ Individualismcollectivism has been long considered an important cultural determinant of loneliness. ${ }^{17} \mathrm{~A}$ recent conceptual model ${ }^{2}$ postulated that risk factors, such as age, interact with triggering events, such as retirement, resulting in feelings of loneliness. Considering that some well established risk factors of loneliness, such as depression ${ }^{18}$ and chronic disease, ${ }^{19}$ are increasing, and that triggering events are part of life (eg, the covid-19 pandemic), it is likely that these risk factors would impact the prevalence of loneliness. Accordingly, loneliness is increasingly recognised as an important health and social issue, with some health professionals, including former US surgeon general Vivek Murthy, labelling it as an epidemic. ${ }^{20}$ In 2018, the United Kingdom appointed the world's first minister for loneliness. Worldwide, initiatives have been launched to address "the epidemic of loneliness."21-23

With loneliness now defined as a public health problem, ${ }^{24}{ }^{25}$ tackling it requires public health approaches, which begin with defining the magnitude and distribution of the problem through surveillance. ${ }^{26}$ A recent estimate suggests that one third of the population in industrialised countries experience loneliness, and one in 12 people experiences loneliness at a problematic level ${ }^{25}$; however, the basis of this estimate is unclear. Understanding the prevalence of loneliness globally can help decision makers gauge the scope and severity of the problem. In light of the covid-19 pandemic, summarising the global prevalence of loneliness before the pandemic would help to identify a prepandemic baseline for subsequent monitoring. Identifying data gaps would also help to inform research endeavours and public health surveillance. In our systematic review and meta-analysis we identified data availability, gaps, and patterns for population level prevalence of loneliness among different age groups globally. We summarised and compared available prevalence estimates within World Health Organization regions when feasible through meta-analysis, and examined temporal trends of loneliness in countries with data.

\section{Methods}

Protocol and data sources

Our reporting conforms to the preferred reporting items for systematic reviews and meta-analyses (PRISMA) guidelines. ${ }^{27}$ The reporting of meta-analysis conforms to the meta-analyses of observational studies in epidemiology (MOOSE) checklist. ${ }^{28}$

We searched for scientific literature published in any language using Embase, Medline, PsycINFO, and
Scopus, supplemented by searching the grey literature using Google Scholar and Open Grey up to 1 September 2021. Search terms included "loneliness", "social isolation”, and "prevalence”, as well as other medical subject headings, truncations, and adjacent operators (supplementary table S1). After duplicates had been removed, additional literature was identified through backwards reference searching.

\section{Eligibility criteria}

Studies were included if they were observational, reported prevalence of loneliness, included data from January 2000 to December 2019 (pre-covid-19 pandemic), and had nationally representative study samples. To ensure population representativeness and comparability across estimates, we excluded studies if the sampling frame or process was inappropriate for assessing the general population ${ }^{29}$ (eg, university students), the sample size was smaller than 292 (calculated using the formula by Naing et al, ${ }^{30}$ with an expected prevalence of 5\%), the measurement instrument was not validated, and the prevalence of chronic or severe loneliness could not be obtained (eg, studies asked about transient loneliness, which is a common experience and not at a problematic level).

\section{Study selection and data extraction}

References were imported into Endnote (Philadelphia, version X8.2) and duplicates removed. Two reviewers (DS, ML) independently screened articles by title and abstract followed by full text and independently extracted study characteristics, including author, population, country, study design, sample size, measurement instrument of loneliness (type, time frame, and operational definition or cut-off points), prevalence estimate, funding role, and conflicts of interest. Disagreements were discussed with a third reviewer (DD) until consensus was reached. Inter-rater agreement was high (94\% for study selection and $93 \%$ for data extraction). When information was missing or ambiguous, we searched for related publications or emailed the authors. When estimates were non-comparable between studies, such as different definitions of loneliness (eg, feeling lonely "often" or "very often"), we tried to harmonise measures by manually recalculating prevalence based on available information or asking the authors to recalculate the prevalence. Risk of bias was assessed based on the Joanna Briggs Institute critical appraisal checklist for prevalence studies, ${ }^{31}$ which is recommended by the Systematic Review Methodology Group for critical appraisal of studies reporting prevalence data. ${ }^{32}$ Two authors (DS and DD) independently assessed risk of bias, with 91\% inter-rater agreement. Differences were resolved by discussion.

\section{Measures of loneliness}

Scale and single item instruments were used to measure loneliness. Because estimates based on the two types of measures were not directly comparable, we summarised prevalence separately. Loneliness is a common experience, thus we excluded transient 
experiences of loneliness ${ }^{5}$ and focused on problematic loneliness, defined by severity (eg, moderate to severe) or chronicity (eg, feeling lonely all the time, usually, or often).

\section{Scale measures}

All selected studies with a scale measure used either the University of California Los Angeles (UCLA) Loneliness Scale ${ }^{33}$ or the de Jong Gierveld Loneliness Scale $^{34}$; both have shown good internal consistency, test-retest reliability, and convergent and discriminant validity. ${ }^{35}$ The de Jong Gierveld scale measures both emotional and social loneliness but can also be used as a unidimensional construct. ${ }^{34}$ Abbreviated versions have been validated for both scales and correlate strongly with their respective original versions. ${ }^{34} 36$ Although certain cut-off points are more commonly used than others, such as $\geq 6$ for the three item UCLA Loneliness Scale, different cut-off points have been selected by authors based on various rationales. We have summarised the cut-off points, documented the differences, and extracted prevalence estimates based on the original cut-off points.

\section{Single item direct measures}

Single item direct measures are the most commonly used assessment tools of loneliness. ${ }^{37}$ Questions were usually worded as "How often do you feel lonely?," with non-substantial variations across studies. Different single item instruments have specified different recall periods, such as in the past week or year, although some did not specify a recall period and asked about general experience. Previous studies found that single item direct measures of loneliness had a moderate correlation with the UCLA Loneliness Scale ${ }^{38}$ and the de Jong Gierveld Loneliness Scale. ${ }^{39}$

\section{Data synthesis}

Narrative review

For all studies we summarised study characteristics, including country, study name, sample size, response rate, sample characteristics (age and sex), and conflict of interest. To demonstrate data availability and gaps, we used MapChart.net to map the availability of classification of country level prevalence of loneliness separately for four age groups (adolescents (12-17 years), young adults (18-29 years), middle aged adults (30-59 years), and older adults ( $\geq 60$ years); fig 1). For studies that applied a scale measure, we tabulated the measurement instrument of loneliness (eg, 20 item UCLA Loneliness Scale, six item de Jong Gierveld Loneliness Scale), country level prevalence of loneliness, and the cut-off points for loneliness at a problematic level. For studies that applied a single item direct measure of loneliness, we summarised the time scale such as past week or year, and the operational definition of loneliness, such as feeling lonely "all the time" or "most of the time."

We summarised data separately for adolescents (12-17 years), young adults (18-29 years), middle aged adults (30-59 years), and older adults $(\geq 60$ years). These age categories reflected the sample characteristics of most studies, although the specific age range could differ. When age categorisations were different from our defined categories, we recalculated age specific prevalence to best match our overall categories. For example, if a study reported the prevalence of loneliness for those aged 60-79 and $\geq 80$ years separately, we recalculated the prevalence for all adults aged $\geq 60$ years based on information presented in the study or obtained through contacting the authors. Similarly, if a study reported loneliness prevalence by sex only, we recalculated prevalence for males and females combined using available or additionally obtained information. Because most studies only reported point estimates for prevalence of loneliness nationally, we used a logit transformation ${ }^{40}$ to obtain pooled variance estimates to calculate 95\% confidence intervals. Finally, we narratively summarised studies that reported multiple measures of loneliness using identical sampling frames, procedures, and instruments over time.

\section{Meta-analysis}

Meta-analysis was conducted for relatively similar studies whenever feasible. We pooled prevalence estimates from studies that applied the same or comparable measures, followed similar study protocols (eg, Global School-Based Student Health Survey), and included similar samples (eg, adolescent school students). In cases when multiple studies reported estimates of loneliness prevalence using identical samples, measures, and surveys, we only included the estimate with the largest analytical sample in the metaanalysis, to avoid double counting. Whenever possible we pooled estimates within WHO regions (Africa, the Americas, Eastern Mediterranean, Europe, South-East Asia, Western Pacific) and conducted subgroup analysis based on the World Bank classification of country income group (low, lower middle, upper middle, and high income countries). For Europe, considering the smaller variability in country income level and the established evidence on geographical difference, particularly the divide between east and west, ${ }^{41} 42$ we conducted subgroup analysis based on modified geographical region classification by the United Nations standard country or area codes for statistical use (M49; https://unstats.un.org/unsd/methodology/m49/), which classified the WHO European region further into northern, southern, eastern, and western Europe, and central and western Asia. For pooled estimates of prevalence and variance, both overall and in subgroups, we used generalised linear mixed effects models with random intercepts by subgroup. ${ }^{40}$ This approach has been used in about $94 \%$ of recent meta-analyses of prevalence estimates. ${ }^{43}$ Binomial-normal models were specified to allow for the calculation of pooled proportion estimates. We conducted additional sensitivity analyses using a double arcsine transformation ${ }^{44}$ to pool prevalence estimates, and reported both $\tau^{2}$ and $\mathrm{I}^{2}$ statistics to describe heterogeneity. ${ }^{45}$ The $\tau^{2}$ estimates between study variability, whereas $\mathrm{I}^{2}$ refers to the 


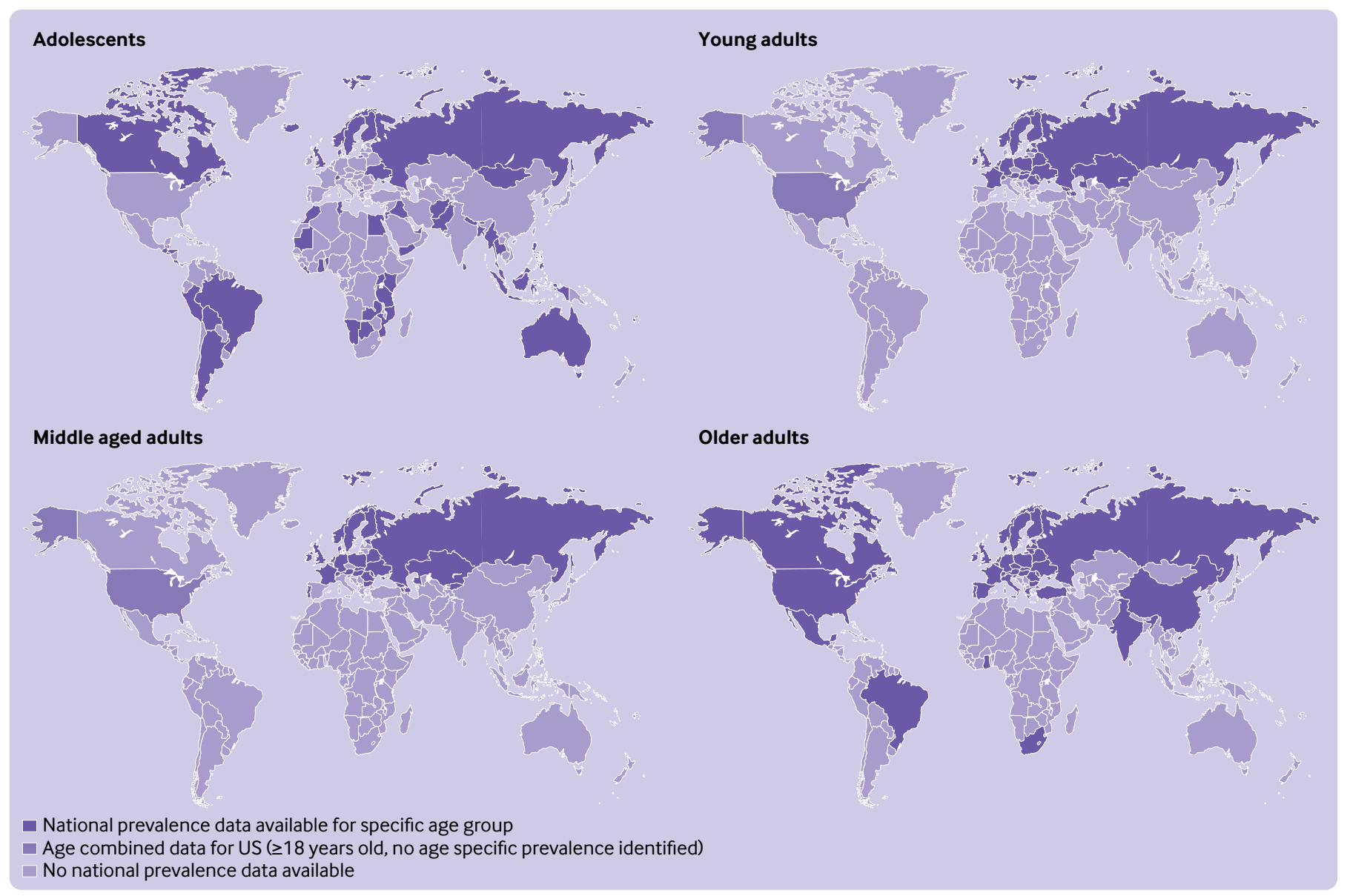

Fig 1 | International estimates for prevalence of loneliness by age groups

proportion of the total variance between studies as a result of "true" variance between populations. ${ }^{4647}$ Metaanalysis was performed in $\mathrm{R}$ (version 4.0.3).

\section{Patient and public involvement}

Patients and members of the public were not involved in the design and execution of the study. However, we plan to engage the public in the dissemination of our findings, including media coverage, social media engagement, newsletters, and public talks and presentations.

\section{Results}

The initial database search yielded 7290 records. After the removal of duplicates, the title and abstract of 2853 were screened, resulting in 194 articles for full text screening. Supplementary figure S1 lists the reasons for exclusion, and supplementary table S2 provides further explanations. Two additional articles were identified through reference searching and three through searches of grey literature. Data on prevalence were extracted from 57 studies for 113 countries or territories.

\section{Data availability}

Eleven studies (nine using the UCLA Loneliness Scale, two using the de Jong Gierveld Loneliness Scale) provided 30 scale based prevalence estimates for 16 countries, and 46 studies provided 295 estimates for prevalence of loneliness measured by single item instruments for 110 countries or territories (supplementary table S3). Across measures, the prevalence of loneliness was identified for adolescents in 77 countries or territories, young adults (18-29 years) in 30 countries, middle aged adults (30-59 years) in 32 countries, and older adults ( $\geq 60$ years) in 40 countries (supplementary table S4). Of those, 212 estimates for 106 countries from 24 studies were included in metaanalyses (supplementary table S5). Supplementary tables S6 and S7 summarise the characteristics of each study. Overall, data showed disparities in loneliness research and surveillance across regions (fig 1) and age groups; while data on adolescents were available across all WHO regions-primarily through the Global School-Based Student Health Survey, data on adults, particularly younger and middle aged adults, were mainly concentrated in Europe.

\section{Risk of bias assessment}

All included studies scored 5-9 out of 9 based on the Joanna Briggs Institute checklist (supplementary table S8). Although all studies met criteria 1 (sampling frame), 3 (sample size), 6 (valid measures), and 7 (standardised measures) as part of this review's 
inclusion criteria, only eight studies (14\%) met criterion 8 (appropriate statistical analysis), mainly because of missing confidence intervals. Around half of the studies (49\%) reported using random probabilistic sampling (criterion 2), whereas the rest did not provide sufficient information on participant recruitment procedures.

\section{Scale measures}

Except for one Australian study ${ }^{48}$ and two American studies, ${ }^{49} 50$ all studies using scale based measures focused on older adults (supplementary table S9). In the meta-analysis of estimates for older adults in 12 countries based on the six item de Jong Gierveld Loneliness Scale, ${ }^{42} 51$ prevalence of loneliness showed a clear geographical pattern (fig 2), with much lower estimates in western European countries (pooled estimate $11.1 \%$, 95\% confidence interval $9.3 \%$ to $13.2 \%)$ than eastern European countries (27.7\%, $21.2 \%$ to $35.3 \%)$. Subgroup effect was statistically significant $(\mathrm{P}<0.01)$; however, variance between studies was high in western and eastern European countries $\left(\tau^{2}=0.047\right.$ and 0.224 , respectively, $\left.\mathrm{P}<0.01\right)$, with this variance mostly related to true differences between populations ( $\mathrm{I}^{2}=94 \%$ and $99 \%$, respectively). In the meta-analysis of 13 estimates derived from the three item UCLA Loneliness Scale for older adults (including subgroup analysis based on different cut-off points), ${ }^{52-56}$ four countries (England, Poland, Spain, and US) had estimates ranging from $9 \%$ to $19 \%$. A fifth country, Finland, had a reported prevalence of 5.9\% (95\% confidence interval $4.7 \%$ to $7.2 \%$ ). No subgroup effect by cut-off point was significant $(\mathrm{P}=0.91)$. Variance between studies was high overall and in subgroups with the same cut-off points.

\section{Single item measures}

Adolescents-Twenty eight studies reported 132 prevalence estimates of loneliness for adolescents in 76 countries (supplementary table S10). Of these, 76 estimates for 68 countries across 17 studies were included in meta-analysis (fig 3, fig 4, fig 5, fig 6), nearly all from the Global School-Based Student Health Survey. Five meta-analyses were conducted, one for each of the following WHO regions: Africa (five studies, ${ }^{57-61} 11$ countries), the Americas (five studies, ${ }^{62-66} 26$ countries), Eastern Mediterranean (two studies, ${ }^{58} 6710$ countries), South-East Asia (five studies, ${ }^{58}$ 68-71 nine countries), and Western Pacific (four studies, ${ }^{5871-73} 12$ countries). A meta-analysis was not performed for Europe owing to fewer comparable measures across a small number of countries with prevalence data for this age group. Pooled prevalence estimates ranged from 9.2\% (95\% confidence interval $6.8 \%$ to $12.4 \%$ ) in South-East Asia to $14.4 \%$ (12.2\% to $17.1 \%$ ) in the Eastern Mediterranean. High heterogeneity was observed in all regions, indicated by high $\tau^{2}$ and $\mathrm{I}^{2}$. Subgroup analysis showed no clear patterns by country income level, although a significant subgroup effect by country income group was detected in Africa and the Americas $(\mathrm{P}<0.05)$.
Young adults-Five studies reported 34 prevalence estimates for young adults (18-29 years) in 30 countries (fig 7). After removing one duplicate (same estimate reported by two studies ${ }^{74} 75$ ), 33 estimates were meta-analysed. All but two estimates ${ }^{39} 76$ came from two multicountry studies: the Europe and Health in Times of Transition study ${ }^{77}$ and the European Social Survey. ${ }^{74}$ The overall pooled prevalence estimate was $5.3 \%(4.4 \%$ to $6.4 \%)$, although dispersion was high $\left(\tau^{2}=0.280, \mathrm{P}<0.01\right)$. When stratification was by the United Nations regional classification, dispersion reduced, although a large proportion remained owing to true variance between populations ( $\mathrm{I}^{2}$ range 44 $85 \%$ ). A statistically significant subgroup difference was detected $(\mathrm{P}<0.01)$, with pooled prevalence being the highest in eastern Europe $(7.5 \%, 5.9 \%$ to $9.4 \%)$ and the lowest in northern Europe $(2.9 \%, 1.8 \%$ to 4.5\%).

Middle aged adults-Four studies reported 36 prevalence estimates for middle aged adults (30-59 years) in 32 countries (fig 8). Similar to studies for young adults, all estimates came from European countries, and all but one $\mathrm{e}^{39}$ came from the Europe and Health in Times of Transition study ${ }^{77}$ (nine countries) and the European Social Survey ${ }^{74}$ (additional 23 countries). After excluding one duplicate estimate, ${ }^{75} 35$ estimates for 32 countries were meta-analysed. ${ }^{397477}$ The pooled prevalence estimate was $6.9 \%$ (5.6\% to $8.6 \%)$, with high dispersion $\left(\tau^{2}=0.483, \quad \mathrm{P}<0.001\right)$. Subgroup difference was significant $(\mathrm{P}<0.01)$, where the pooled prevalence was the lowest in northern Europe $(2.7 \%$, $2.4 \%$ to $3.0 \%$ ) and highest in eastern Europe (9.6\%, $7.7 \%$ to $12.0 \%)$ and central and western Asia (9.8\%, $5.1 \%$ to $18.0 \%)$.

Older adults-Seventeen studies reported 93 prevalence estimates for 38 countries, including 30 European countries and eight non-European countries (fig 9). A total of 43 estimates from 30 European countries were included in meta-analysis. All but two estimates ${ }^{39} 78$ came from large multicountry studies: the Europe and Health in Times of Transition study, ${ }^{77}$ the European Social Survey, ${ }^{74}$ and the Survey of Health, Ageing, and Retirement in Europe. ${ }^{79}$ Overall dispersion was high $\left(\tau^{2}=0.461, \mathrm{P}<0.01\right)$. Although less variability was shown within geographical subgroup, the proportion of observed variance due to true differences between populations remained high $\left(\mathrm{I}^{2}\right.$ range 78-89\%). Subgroup difference was significant $(\mathrm{P}<0.01)$, where northern European countries had the lowest pooled prevalence $(5.2 \%, 4.2 \%$ to $6.5 \%)$, followed by western Europe $(8.7 \%, 7.3 \%$ to $10.5 \%)$, southern Europe $(15.7 \%, 13.2 \%$ to $18.7 \%)$, and eastern European countries had the highest prevalence of loneliness $(21.3 \%, 18.7 \%$ to $24.2 \%)$.

\section{Sensitivity analysis}

For meta-analysis of loneliness prevalence in younger, middle aged, and older adults in Europe, additional analysis was conducted using the World Bank country income group for subgroups. For young adults, no evidence was found for statistically significant 


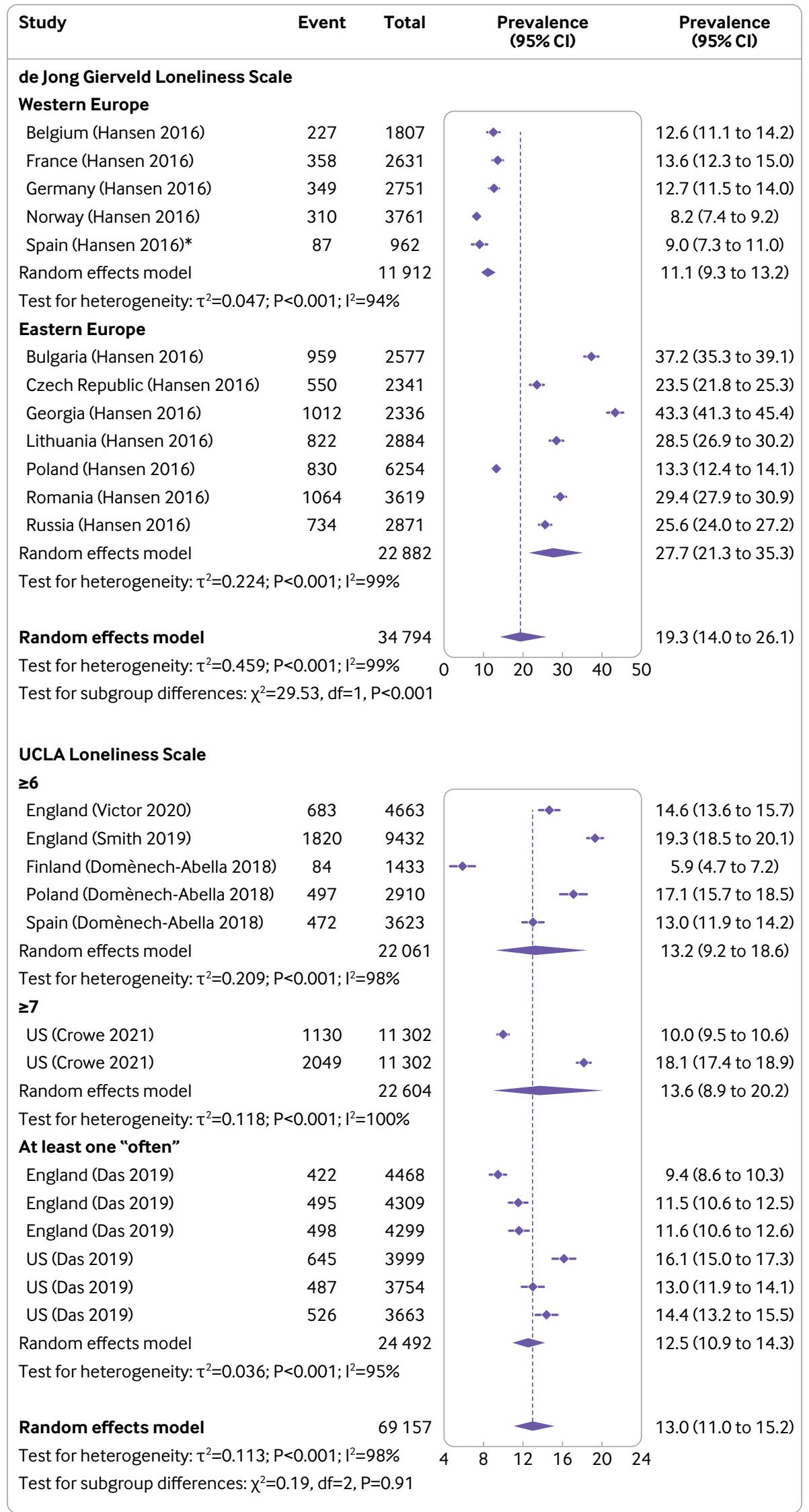

Fig 2 | Meta-analysis of loneliness prevalence using scale based measures (de Jong Gierveld Loneliness Scale, six item version, and University of California Los Angeles (UCLA) Loneliness Scale, three item version) in older adults ( $\geq 60$ years). *Thresholds of five or six were applied. Generalised linear mixed effects models with binomial-normal distribution were used. Norway is included as part of western Europe owing to the lack of data from other northern European countries 


\begin{tabular}{|c|c|c|c|c|c|}
\hline Study & Event & Total & $\begin{array}{r}\text { Prevale } \\
(95 \%\end{array}$ & $\begin{array}{l}\text { lence } \\
6 \mathrm{Cl})\end{array}$ & $\begin{array}{l}\text { Prevalence } \\
(95 \% \mathrm{Cl})\end{array}$ \\
\hline \multicolumn{6}{|l|}{ Africa } \\
\hline \multicolumn{6}{|l|}{ Low income countries } \\
\hline Benin (Vancampfort 2019) & 75 & 717 & $\longrightarrow \bullet$ & & $10.5(8.3$ to 12.9$)$ \\
\hline Liberia (Pengpid 2020) & 367 & 2640 & & & 13.9 (12.6 to 15.3$)$ \\
\hline Mozambique (Vancampfort 2019) & 53 & 668 & $\longrightarrow-$ & & $7.9(6.0$ to 10.2$)$ \\
\hline Tanzania (Vancampfort 2019) & 108 & 1615 & $-\bullet-$ & & $6.7(5.5$ to 8.0$)$ \\
\hline Tanzania (Seidu 2019) & 104 & 1500 & $-\bullet-$ & & $6.9(5.7$ to 8.3$)$ \\
\hline Tanzania (Amu 2020) & 426 & 2449 & & $\rightarrow-$ & 17.4 (15.9 to 19.0$)$ \\
\hline Uganda (Vancampfort 2019) & 177 & 1904 & $-\bullet-$ & & $9.3(8.0$ to 10.7$)$ \\
\hline Random effects model & & 11493 & $\sim$ & & 9.9 (7.7 to 12.7$)$ \\
\hline \multicolumn{6}{|c|}{ Test for heterogeneity: $\tau^{2}=0.137 ; P<0.01 ; I^{2}=97 \%$} \\
\hline \multicolumn{6}{|l|}{ Lower middle income countries } \\
\hline Ghana (Baiden 2019) & 291 & 1633 & & $\longrightarrow-$ & $17.8(16.0$ to 19.8$)$ \\
\hline Kenya (Vancampfort 2019) & 529 & 2971 & & $-\bullet-$ & $17.8(16.4$ to 19.2$)$ \\
\hline Mauritania (Vancampfort 2019) & 211 & 1285 & & $-\bullet-$ & 16.4 (14.4 to 18.6$)$ \\
\hline Zambia (Vancampfort 2019) & 322 & 1365 & & $\rightarrow$ & $23.6(21.4$ to 25.9$)$ \\
\hline Random effects model & & 7254 & & $\longrightarrow$ & $18.8(16.4$ to 21.4$)$ \\
\hline \multicolumn{6}{|c|}{ Test for heterogeneity: $\tau^{2}=0.025 ; P<0.01 ; I^{2}=89 \%$} \\
\hline \multicolumn{6}{|c|}{ Upper middle income countries } \\
\hline Botswana (Vancampfort 2019) & 201 & 1397 & & & 14.4 (12.6 to 16.3 ) \\
\hline Namibia (Vancampfort 2019) & 242 & 1936 & & & $12.5(11.1$ to 14.1$)$ \\
\hline Random effects model & & 3333 & 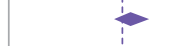 & & $13.3(12.1$ to 14.7$)$ \\
\hline \multicolumn{6}{|c|}{ Test for heterogeneity: $\tau^{2}=0.001 ; P=0.11 ; I^{2}=60 \%$} \\
\hline Random effects model & & 22080 & & & $12.7(10.3$ to 15.7$)$ \\
\hline Test for heterogeneity: $\tau^{2}=0.187 ; P$ & $=0.01 ; 1^{2}=$ & $7 \%$ & 10 & 20 & \\
\hline
\end{tabular}

Fig 3 | Meta-analysis of loneliness prevalence based on single item measures in adolescents (12-17 years) by World Health Organization Africa region. Generalised linear mixed effects models with binomial-normal distribution were used

subgroup differences $(\mathrm{P}=0.35)$ (supplementary figure S3). For middle aged and older adults (both using the de Jong Gierveld Loneliness Scale and single item measures), high income European countries had a lower pooled prevalence than middle income European countries, and the subgroup difference was statistically significant (supplementary figures S2, S4, S5). Additional sensitivity analysis using the FreemanTukey double arcsine transformation approach to meta-analyses resulted in nearly identical findings ${ }^{80}$ (supplementary figures S6-10).

\section{Temporal trends in loneliness}

Four studies reported multiple comparable prevalence estimates of loneliness based on repeated cross sectional surveys. One study in Danish school children (11-15 years old) found that the prevalence of loneliness increased from $4.4 \%$ (95\% confidence interval $3.4 \%$ to $5.4 \%$ ) in 1991 to $7.2 \%$ (6.4\% to $8.0 \%$ ) in $2014(\mathrm{P}<0.001$ for trend $) .{ }^{81}$ Similarly a significant and steady increase in loneliness was found in Norwegian secondary school children, from 9.0\% (95\% confidence interval $8.5 \%$ to $9.5 \%$ ) in 2014 to $12.1 \%$ $(11.7 \%$ to $12.5 \%)$ in $2018(\mathrm{P}<0.001) .{ }^{82}$ Additionally, a study found no change in loneliness prevalence among adolescent school students between 2005 and 2016 in the United Arab Emirates $(\mathrm{P}>0.05) .{ }^{67}$ Finally, a study in adults aged 77 years or older in Sweden found no significant trend in prevalence of loneliness from 1992 to $2014(\mathrm{P}=0.71) .^{83}$

\section{Discussion}

Based on data from 113 countries or territories during 2000-19, we found that loneliness at a problematic level is a common experience worldwide. We further identified important data gaps and substantial geographical variation in loneliness. Considering the physical, mental, and social health consequences of loneliness, our study findings reinforce the urgency of approaching loneliness as an important public health issue. $^{2425}$

Although 113 countries or territories reported some data on loneliness prevalence, globally there is still a dearth of data across broader geographical areas. International surveillance systems, such as the Global School-Based Student Health Survey, are important for priority setting, benchmarking progress, and cross country comparisons. The Global School-Based 


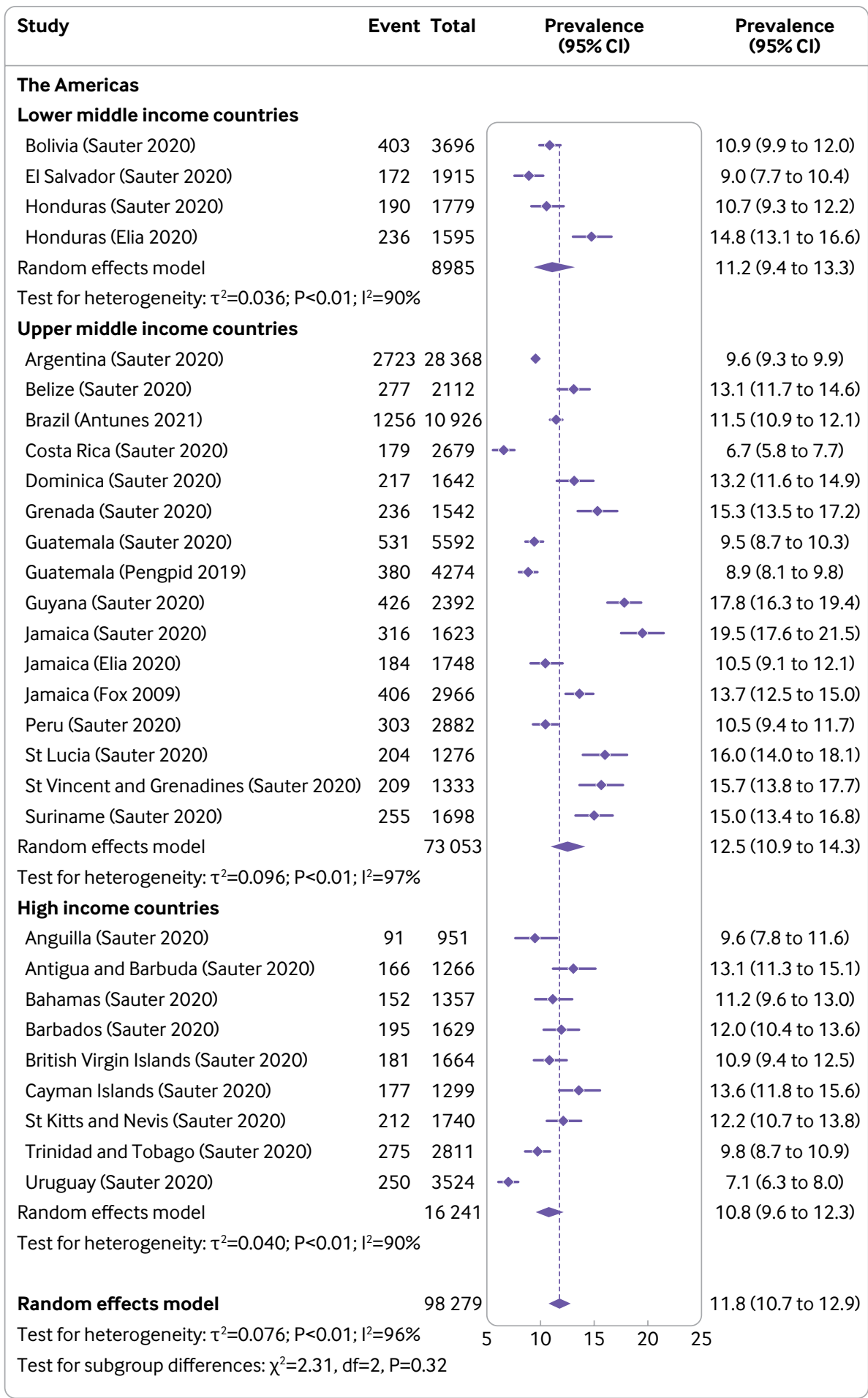

Fig 4 | Meta-analysis of loneliness prevalence based on single item measures in adolescents (12-17 years) by World Health Organization The Americas region. Generalised linear mixed effects models with binomial-normal distribution were used

Student Health Survey has provided valuable data for loneliness in children and adolescents in 67 countries or territories, most of which are low and middle income countries. Disparities still exist in data availability across WHO regions and country income levels. While Europe is leading in loneliness research and surveillance with a wealth of data sources, such as the Survey of Health, Ageing, and Retirement in
Europe, the European Social Survey, and the Europe and Health in Times of Transition study, other regions and most low and middle income countries have much less data coverage. Importantly, no low income countries and only five of all 47 lower middle income countries have reported any nationally representative data on loneliness in adults. Such data gaps might be a result of limited resources and competing priorities 


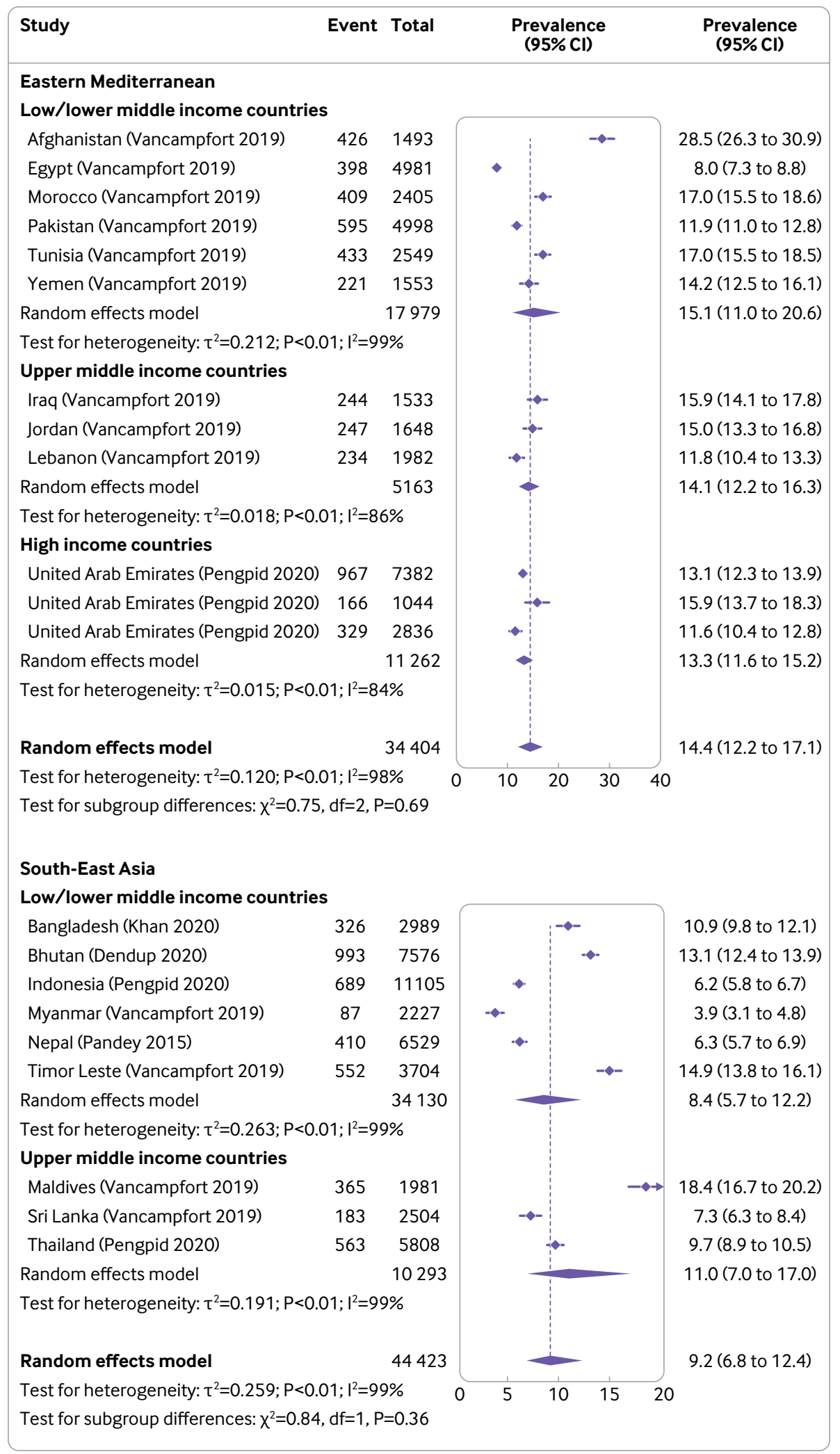

Fig 5 | Meta-analysis of loneliness prevalence based on single item measures in adolescents (12-17 years) by World Health Organization Eastern Mediterrean and South-East Asia regions. Generalised linear mixed effects models with binomial-normal distribution were used

from issues deemed more urgent, such as food security, housing, and basic provision of medical services. $^{84}$
Data on loneliness prevalence is also lacking for young and middle aged adults, compared with adolescents and older adults. Such data gaps could 


\begin{tabular}{|c|c|c|c|c|}
\hline Study & Event & Total & $\begin{array}{l}\text { Prevalence } \\
(95 \% \mathrm{Cl})\end{array}$ & $\begin{array}{l}\text { Prevalence } \\
(95 \% \mathrm{Cl})\end{array}$ \\
\hline \multicolumn{5}{|l|}{ Western Pacific } \\
\hline \multicolumn{5}{|l|}{ Lower middle income countries } \\
\hline Kiribati (Vancampfort 2019) & 66 & 1340 & $\bullet-$ & 4.9 (3.8 to 6.2$)$ \\
\hline Laos (Pengpid 2020) & 148 & 3699 & $\bullet$ & 4.0 (3.4 to 4.7$)$ \\
\hline Mongolia (Vancampfort 2019) & 423 & 3707 & 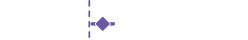 & 11.4 (10.4 to 12.5$)$ \\
\hline Philippines (Pengpid 2020) & 1408 & 8747 & $\bullet$ & $16.1(15.3$ to 16.9$)$ \\
\hline Solomon Islands (Vancampfort 2019) & 111 & 925 & & $12.0(10.0$ to 14.3$)$ \\
\hline Vanuatu (Vancampfort 2019) & 63 & 852 & $-\bullet-$ & $7.4(5.7$ to 9.4$)$ \\
\hline Random effects model & & 19270 & & $8.4(5.6$ to 12.5$)$ \\
\hline \multicolumn{5}{|c|}{ Test for heterogeneity: $\tau^{2}=0.295 ; P<0.01 ; I^{2}=99 \%$} \\
\hline \multicolumn{5}{|c|}{ Upper middle income countries } \\
\hline Fiji (Vancampfort 2019) & 186 & 1537 & $\leftrightarrow-$ & 12.1 (10.5 to 13.8$)$ \\
\hline Malaysia (Tan 2019) & 2479 & 27458 & $\bullet$ & 9.0 (8.7 to 9.4$)$ \\
\hline Malaysia (Vancampfort 2019) & 1107 & 16273 & $\bullet$ & $6.8(6.4$ to 7.2$)$ \\
\hline Samoa (Vancampfort 2019) & 508 & 2200 & $-\diamond-$ & 23.1 (21.3 to 24.9 ) \\
\hline Tonga (Vancampfort 2019) & 304 & 1946 & $-\bullet-$ & $15.6(14.0$ to 17.3$)$ \\
\hline Tuvalu (Vancampfort 2019) & 56 & 679 & $\rightarrow-\frac{1}{1}$ & $8.2(6.3$ to 10.6$)$ \\
\hline Random effects model & & 50093 & & $11.6(8.2$ to 16.1$)$ \\
\hline \multicolumn{5}{|c|}{ Test for heterogeneity: $\tau^{2}=0.227 ; P<0.01 ; 1^{2}=99 \%$} \\
\hline \multicolumn{5}{|c|}{ High income countries } \\
\hline Brunei (Shahedifar 2020) & 312 & 2599 & $\leftrightarrow-$ & $12.0(10.8$ to 13.3$)$ \\
\hline Random effects model & & 2599 & $\rightarrow$ & $12.0(10.8$ to 13.3$)$ \\
\hline \multicolumn{5}{|l|}{ Test for heterogeneity: not applicable } \\
\hline Random effects model & & 71962 & $\dot{L}$ & 10.0 (7.7 to 12.9$)$ \\
\hline \multicolumn{5}{|c|}{ Test for heterogeneity: $\tau^{2}=0.271 ; P<0.01 ; I^{2}=99 \%$} \\
\hline \multicolumn{5}{|c|}{ Test for subgroup differences: $\chi^{2}=2.94, d f=2, P=0.23$} \\
\hline & & 0 & 20 & 30 \\
\hline
\end{tabular}

Fig 6 | Meta-analysis of loneliness prevalence based on single item measures in adolescents (12-17 years) by World Health Organization Western Pacific region. Generalised linear mixed effects models with binomial-normal distribution were used

be driven by the widely held belief that middle aged adults are the least susceptible to loneliness, and that young and old people are particularly vulnerable because of the changes experienced during these life stages. ${ }^{85}$ Although our meta-analysis based on European data suggests that young and middle aged adults have a lower prevalence of loneliness compared with their older adult counterparts, findings from the AARP national loneliness survey ${ }^{49}$ and the 2020 Cigna Report ${ }^{50}$ from the US suggested otherwise. According to the Australian Loneliness Report, adults aged between 36 and 65 years reported consistently higher loneliness scores than those aged between 26 and 35 years, and those aged 65 and older. ${ }^{86}$ Such findings suggest that the age pattern of loneliness might be context specific, although more data are needed among the general adult population to fully understand the susceptibility to loneliness throughout the lifespan. ${ }^{87}$

Based on our meta-analysis, the prevalence of loneliness is highly heterogenous across countries, even within the same region. While insufficient data prevented us from identifying geographical patterns of loneliness outside of Europe, within Europe the pattern is clear and consistent. Across different adult age groups, northern European countries consistently reported the lowest prevalence of loneliness, whereas eastern European countries reported the highest. One study attributed country level differences to demographic characteristics, health status, social participation, and social support. ${ }^{41}$ Others have cited welfare systems and social security schemes as contributing factors, ${ }^{42}$ as welfare generosity has been positively linked to social participation and inversely associated with social exclusion. ${ }^{88}$ A previous metaanalysis found an inverse association between socioeconomic status and loneliness. ${ }^{89}$ A combination of high socioeconomic status, overall health, welfare generosity, and high social participation could explain the low levels of loneliness in northern European countries. In contrast, eastern European countries tend to have poorer health outcomes, healthcare services, and state welfare. ${ }^{41}$ Other demographic characteristics, such as large gaps in life expectancy between men and women (hence a high proportion of widows) and increasing emigration among young people, might have contributed. ${ }^{42}$ Changes associated with transition from socialism, such as reductions in pensions paired with rising living expenses, change in 


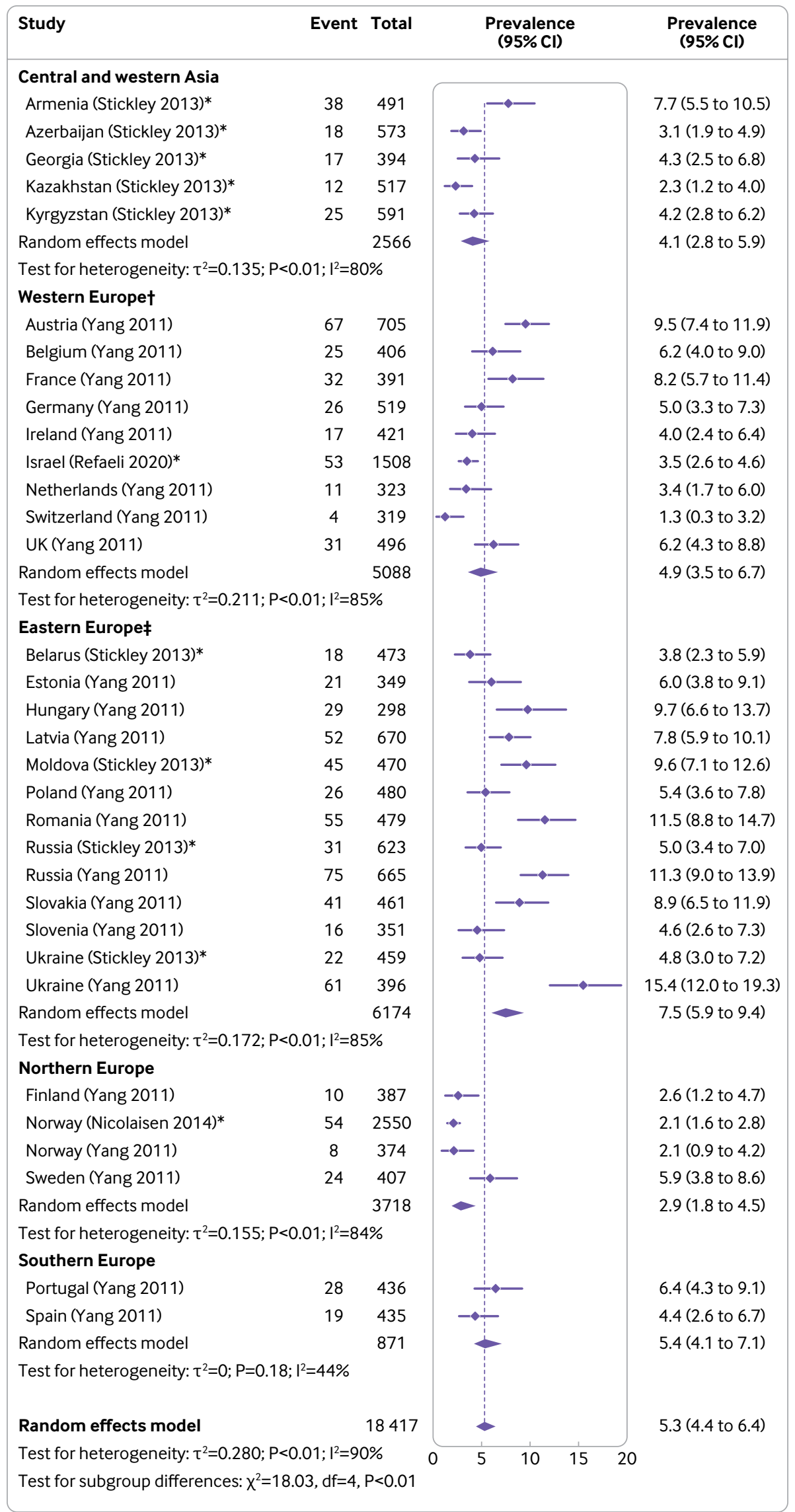

Fig 7 | Meta-analysis of loneliness prevalence based on single item measures in young adults (18-29 years) in Europe. Generalised linear mixed effects models with binomial-normal distribution were used. *Unspecified recall period; past week otherwise. IIncludes Israel. ¥Includes Georgia 


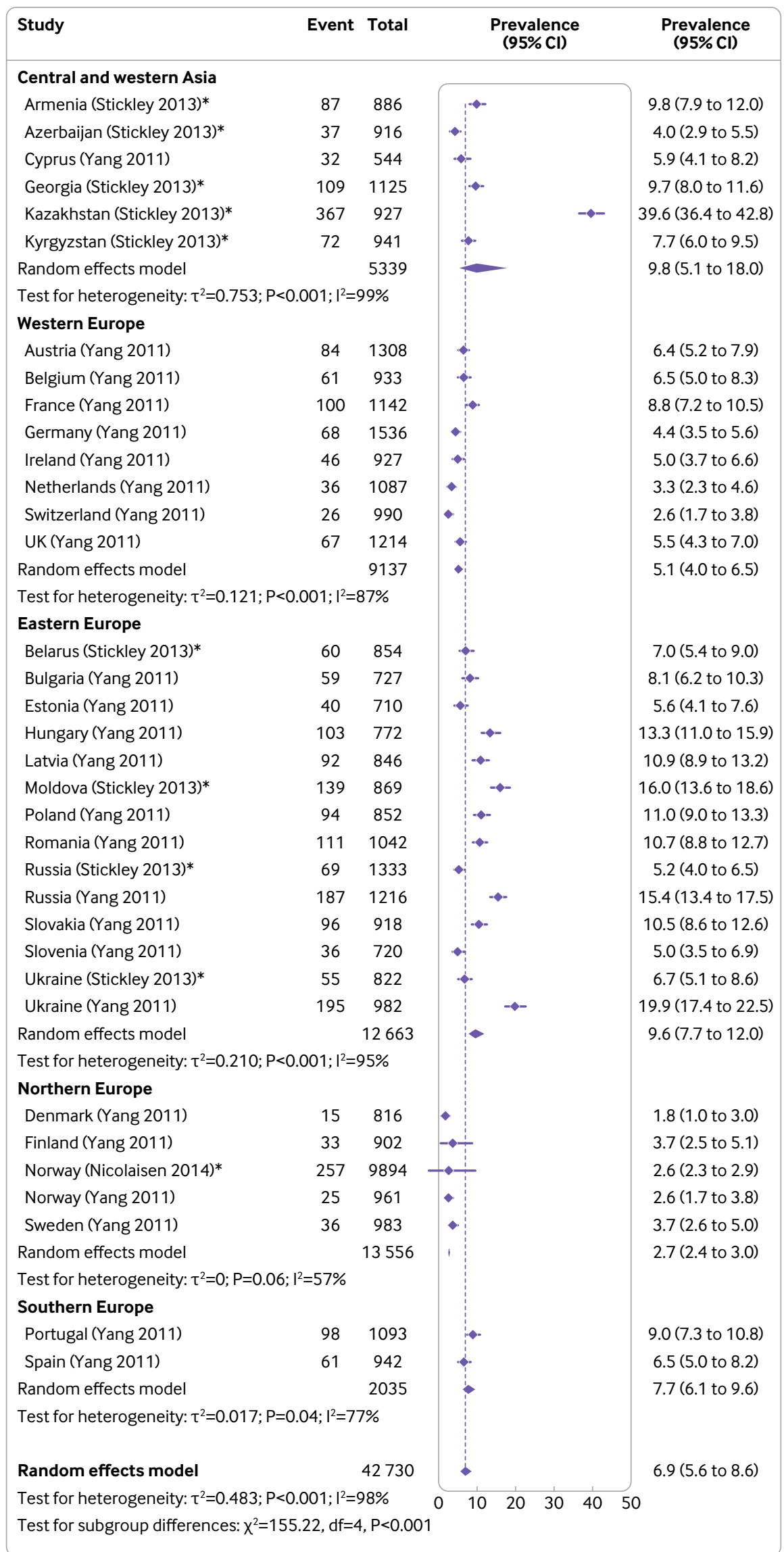

Fig 8 | Meta-analysis of loneliness prevalence based on single item measures in middle aged adults (30-59 years) in Europe. Generalised linear mixed effects models with binomial-normal distribution were used. *Unspecified recall period; past week otherwise 


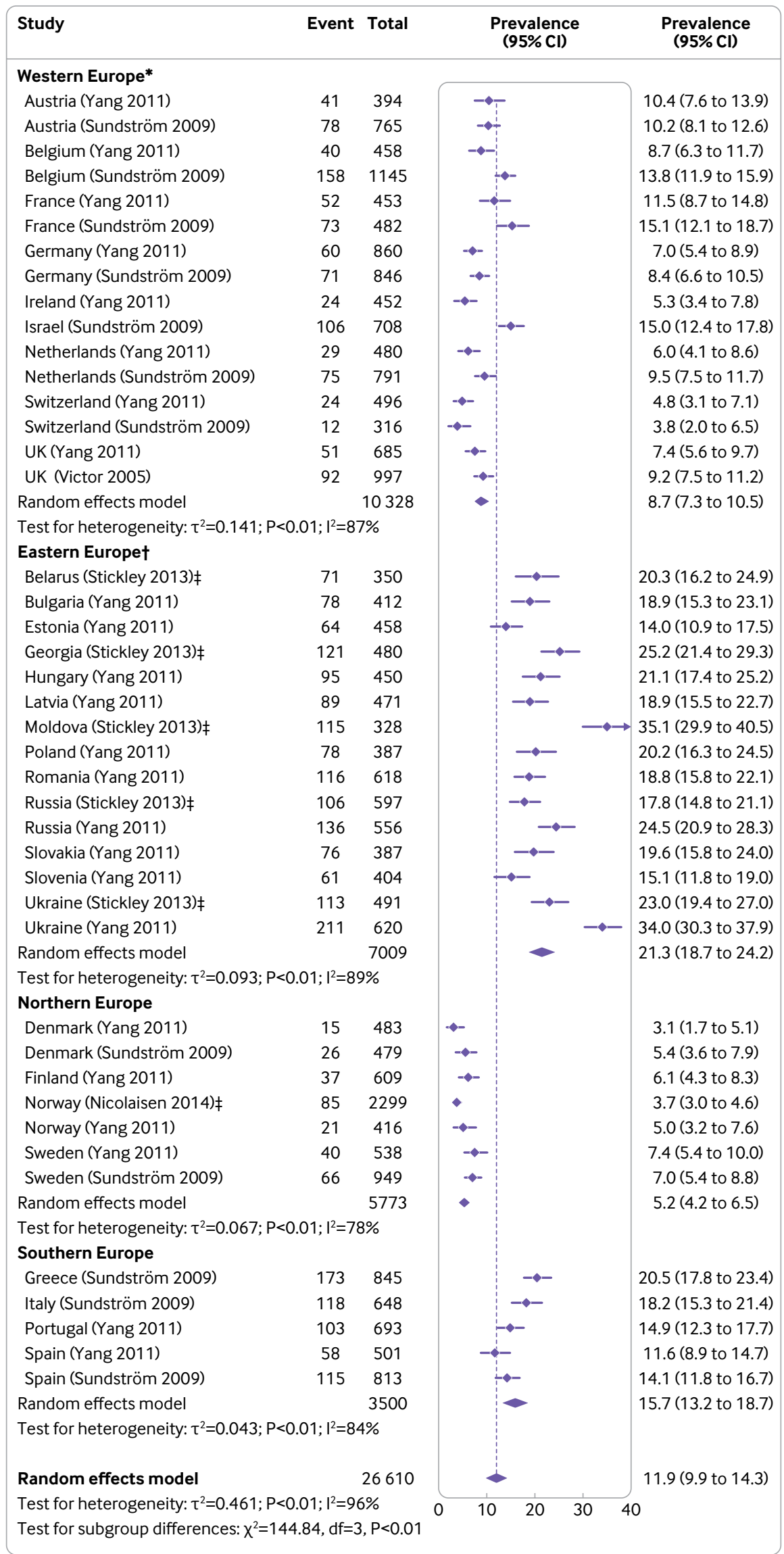

Fig 9 | Meta-analysis of loneliness prevalence based on single item measures in older adults ( $\geq 60$ years) in Europe. Generalised linear mixed effects models with binomial-normal distribution were used. *Includes Israel. tIncludes Georgia. ¥Unspecified recall period; past week otherwise 
care arrangements, and reduced social trust are also potential explanations for high levels of loneliness in eastern Europe. ${ }^{4190}$

Despite media and public dialogue describing loneliness as a worsening social problem, ${ }^{91}{ }^{92}$ we found insufficient evidence to support this claim. We only identified four studies that repeatedly examined loneliness using comparable measures over time, and the findings from these studies were mixed. Even if the problem of loneliness had not worsened during our search period (2000-19), covid-19 might have had a profound impact on loneliness. ${ }^{9394}$ In this context, our review provides an important prepandemic baseline for future surveillence.

\section{Strengths and limitations of this study}

To maximise the validity of our findings, we limited our study selection to those based on nationally representative samples, sufficient sample sizes, and validated instruments. We maximised comparability across studies by harmonising results when feasible and summarising findings according to measurement instrument and age groups. However, our findings should be interpreted in light of weaknesses. Comprehensive global comparison and quantitative synthesis is limited by heterogeneity in study design, sampling procedures, and measurement instruments. Despite our attempts to improve comparability through harmonisation and stratification, we still found considerable evidence of heterogeneity, even within smaller subgroups of regions. Such heterogeneity is common in meta-analyses of prevalence, ${ }^{43}$ and the pooled estimates should be interpreted as indicative only.

Understanding loneliness as a global health issue requires data from most countries-however, data are lacking for most regions outside of Europe. Meanwhile, the lack of repeated measurements limited our conclusions about temporal trends. Additionally, no studies explicitly reported elements of "co-design" with the intended communities. This might be the case particularly for translated instruments. Even though the instruments reviewed in our study have been translated, validated, and widely used in many countries, cross cultural adaptations of these questions could have limitations. ${ }^{95}$ What loneliness means in one cultural and linguistic context might not be the same in another.

Differences in age groups and survey time also introduced additional complications. Although we limited study selection to those with data from 2000 to 2019, estimates in some countries could be more than 10 years older than those from other countries. Despite our attempts to provide prevalence estimates for different age groups, specific age categories differed by study, further limiting comparability across studies. Finally, different interpretation and operationalisation of loneliness (eg, cut-off points, recall time frame) across countries may lead to differential reporting biases. Because no single definition of problematic loneliness exists, what was labelled as "problematic" varied (eg, severity versus chronicity). This poses further challenges in interpreting prevalence across countries.

\section{Strengths and limitations in relation to other studies}

Another systematic review on the prevalence of loneliness has been peformed. ${ }^{96}$ This review, however, was of a narrower scope than ours, as it only synthesised studies among older adults in high income countries published between 2008 and 2020. This review was subject to methodological limitations, such as not considering population representativeness and not accounting for different measurement instruments or operational definitions of loneliness across studies.

In early 2021, researchers reported the prevalence of loneliness for adults in 237 countries and territories based on the BBC loneliness experiment dataset. ${ }^{97}$ As a primary study (in contrast with our systematic review and meta-analysis), it benefited from being able to apply the same measurement instrument to all participants and directly model predictors of loneliness, such as age, sex, and individualism, of the country of residence. Participants were, however, recruited as a convenience sample through BBC programmes (presumably in English only) and thus were not representative of populations-32\% of the participants were men and $74 \%$ were UK residents. Therefore, prevalence estimates derived from this study are unlikely to be representative of the countries and territories.

\section{Meaning of the study}

We advocate among health professionals, decision makers, and the general public for better awareness of widespread loneliness. The data gaps in low and middle income countries raised an important issue of equity. Public health efforts to prevent and reduce loneliness require well coordinated ongoing surveillance across different lifes stages and broad geographical areas. High quality data based on validated and comparable instruments are urgently needed to tackle loneliness. Sizeable differences in prevalence of loneliness across countries and regions call for in-depth investigation to unpack the drivers of loneliness at systemic levels and to develop interventions to deal with them.

\section{Recommendations for future research}

Measurement is an ongoing challenge in loneliness research and surveillance. Researchers have previously documented the difficulty in comparing estimates of loneliness prevalence across studies and advocated for maximising comparability across survey instruments. ${ }^{39}$ Conflicting evidence resulting from different definitions and measurements of loneliness has been identified as a major challenge. ${ }^{84}$ One fundamental difference between measures is that single item questions directly asked about "loneliness," but scales exclude direct reference to loneliness. Therefore, single item estimates might consistently misclassify loneliness. The UK Office for National Statistics recommends 
using both direct and indirect scale measures of loneliness when possible, and using direct single item questions when constrained by space. ${ }^{37}$ Future studies could benefit from probabilistic sampling, repeated measures, and sufficient reporting of prevalence (eg, including uncertainty in addition to point estimates). Finally, considering the potential impact of covid-19 on social health worldwide, we encourage more studies to track long term trends of loneliness across the lifespan using the estimates we summarised as a prepandemic baseline for comparison.

Contributors: DS, KG, and DD conceived the study. DS, AB, and DD developed the review protocol. DS and DD conducted the literature search. DS and ML independently screened the studies, extracted data, and discussed results with DD. DS, RE, and DD conducted the literature search. JvB conducted the meta-analysis. DS and DD drafted the manuscript. All authors provided critical input during the writing and revision of the paper. DD supervised the study. DS, ML, and DD are the guarantors. The corresponding author attests that all listed authors meet authorship criteria and that no others meeting the criteria have been omitted.

Funding: None received.

Competing interests: All authors have completed the ICMJE uniform disclosure form at www.icmje.org/coi_disclosure.pdf and declare no support from any organisation for the submitted work; no financial relationships with any organisations that might have an interest in the submitted work in the previous three years; no other relationships or activities that could appear to have influenced the submitted work.

Ethical approval: Not required.

Data sharing: No additional data available.

The lead author (DS) affirms that this manuscript is an honest, accurate, and transparent account of the study being reported; that no important aspects of the study have been omitted; and that any discrepancies from the study as planned (and, if relevant, registered) have been explained.

Dissemination to participants and related patient and public communities: The authors plan to disseminate the findings of this research to the public communities through media outlets, social media engagement, talks, and presentations.

Publisher's note: Published maps are provided without any warranty of any kind, either express or implied. BMJ remains neutral with regard to jurisdictional claims in published maps.

Provenance and peer review: Not commissioned; externally peer reviewed.

This is an Open Access article distributed in accordance with the Creative Commons Attribution Non Commercial (CC BY-NC 4.0) license, which permits others to distribute, remix, adapt, build upon this work non-commercially, and license their derivative works on different terms, provided the original work is properly cited and the use is noncommercial. See: http://creativecommons.org/licenses/by-nc/4.0/.

1 Peplau LA, Perlman D. Perspective on loneliness. Loneliness: A sourcebook of current theory, research and therapy. John Wiley and Sons, 1982: 1-18.

$2 \operatorname{Lim} M \mathrm{MH}$, Eres R, Vasan S. Understanding loneliness in the twenty-first century: an update on correlates, risk factors, and potential solutions. Soc Psychiatry Psychiatr Epidemiol 2020;5 5:793-810. doi:10.1007/ s00127-020-01889-7

3 Masi CM, Chen H-Y, Hawkley LC, Cacioppo JT. A meta-analysis of interventions to reduce loneliness. Pers Soc Psychol Rev 2011;15:219-66. doi:10.1177/1088868310377394

4 Yanguas J, Pinazo-Henandis S, Tarazona-Santabalbina FJ. The complexity of loneliness. Acta Biomed 2018;89:302-14. doi:10.23750/abm.v89i2.7404

5 Baumeister RF, Leary MR. The need to belong: desire for interpersonal attachments as a fundamental human motivation. Psychol Bull 1995;117:497-529. doi:10.1037/0033-2909.117.3.497

6 Hodgson S, Watts I, Fraser S, Roderick P, Dambha-Miller H. Loneliness, social isolation, cardiovascular disease and mortality: a synthesis of the literature and conceptual framework. J R Soc Med 2020;113:185-92. doi:10.1177/0141076820918236

7 Leigh-Hunt N, Bagguley D, Bash K, et al. An overview of systematic reviews on the public health consequences of social isolation and loneliness. Public Health 2017;152:157-71. doi:10.1016/j. puhe.2017.07.035
8 Valtorta NK, Kanaan M, Gilbody S, Ronzi S, Hanratty B. Loneliness and social isolation as risk factors for coronary heart disease and stroke: systematic review and meta-analysis of longitudinal observational studies. Heart 2016;102:1009-16. doi:10.1136/ heartjnl-2015-308790

9 Griffin SC, Williams AB, Ravyts SG, Mladen SN, Rybarczyk BD. Loneliness and sleep: A systematic review and metaanalysis. Health Psychol Open 2020;7:2055102920913235. doi:10.1177/2055102920913235

10 Lara E, Martín-María N, De la Torre-Luque A, et al. Does loneliness contribute to mild cognitive impairment and dementia? A systematic review and meta-analysis of longitudinal studies. Ageing Res Rev 2019:52:7-16. doi:10.1016/j.arr.2019.03.002

11 McClelland H, Evans JJ, Nowland R, Ferguson E, O'Connor RC. Loneliness as a predictor of suicidal ideation and behaviour: a systematic review and meta-analysis of prospective studies. I Affect Disord 2020;274:880-96. doi:10.1016/j.jad.2020.05.004

12 Wang J, Mann F, Lloyd-Evans B, Ma R, Johnson S. Associations between loneliness and perceived social support and outcomes of mental health problems: a systematic review. BMC Psychiatry 2018;18:156. doi:10.1186/s12888-018-1736-5

13 Holt-Lunstad I, Smith TB, Baker M, Harris T, Stephenson D. Loneliness and social isolation as risk factors for mortality: a meta-analytic review. Perspect Psychol Sci 2015;10:227-37. doi:10.1177/1745691614568352

14 Lee IM, Shiroma EJ, Lobelo F, Puska P, Blair SN, Katzmarzyk PT, et al, Lancet Physical Activity Series Working Group. Effect of physical inactivity on major non-communicable diseases worldwide: an analysis of burden of disease and life expectancy. Lancet 2012;380:219-29. doi:10.1016/S0140-6736(12)61031-9

15 Di Angelantonio E, Bhupathiraju ShN, Wormser D, et al, Global BMI Mortality Collaboration. Body-mass index and all-cause mortality: individual-participant-data meta-analysis of 239 prospective studies in four continents. Lancet 2016;388:776-86. doi:10.1016/S01406736(16)30175-1

16 Lykes VA, Kemmelmeier M. What predicts loneliness? Cultural difference between individualistic and collectivistic societies in Europe. J Cross Cult Psychol 2014;45:468-90. doi:10.1177/0022022113509881

17 Heu LC, van Zomeren M, Hansen N. Lonely alone or lonely together? A cultural-psychological examination of individualism-collectivism and loneliness in five European countries. Pers Soc Psychol Bull 2019;45:780-93. doi:10.1177/0146167218796793

18 Hidaka BH. Depression as a disease of modernity: explanations for increasing prevalence. J Affect Disord 2012;140:205-14 doi:10.1016/j.jad.2011.12.036

19 van Oostrom SH, Giisen R, Stirbu I, et al. Time trends in prevalence of chronic diseases and multimorbidity not only due to aging: data from general practices and health surveys. PLoS One 2016;11:e0160264 doi:10.1371/journal.pone.0160264

20 Murthy V. Work and the loneliness epidemic. Harv Bus Rev. Harvard Business Publishing, 2017: 9.

21 Ending Loneliness Together in Australia. About us. https:// endingloneliness.com.au/about-us/.

22 Campaign to End Loneliness. About the Campaign. https://www. campaigntoendloneliness.org/about-the-campaign/.

23 Coalition to End Social Isolation \& Loneliness. www. endsocialisolation.org/.

24 Hunter D. Loneliness: a public health issue. Perspect Public Health 2012;132:153. doi:10.1177/1757913912449564

25 Cacioppo JT, Cacioppo S. The growing problem of loneliness. Lancet 2018;391:426. doi:10.1016/S0140-6736(18)30142-9

26 Violence Prevention Alliance. The public health approach Geneva: World Health Organization; 2020. www.who.int/violenceprevention/ approach/public_health/en/.

27 Moher D, Liberati A, Tetzlaff J, Altman DG, PRISMA Group. Preferred reporting items for systematic reviews and meta-analyses: the PRISMA statement. BMJ 2009;339:b2535. doi:10.1136/bmj.b2535

28 Brooke BS, Schwartz TA, Pawlik TM. MOOSE Reporting Guidelines for Meta-analyses of Observational Studies. JAMA Surg 2021;156:7878. doi:10.1001/jamasurg.2021.0522

29 Munn Z, Moola S, Lisy K, Riitano D, Tufanaru C. Methodological guidance for systematic reviews of observational epidemiological studies reporting prevalence and cumulative incidence data. Int J Evid Based Healthc 2015;13:147-53. doi:10.1097/XEB.0000000000000054

30 Naing L, Winn T, Rusli BN. Practical issues in calculating the sample size for prevalence studies. Arch Orofac Sci 2006;1:9-14.

31 Munn Z, Moola S, Lisy K, Riitano D, Tufanaru C. Methodological guidance for systematic reviews of observational epidemiological studies reporting prevalence and cumulative incidence data. Int J Evid Based Healthc 2015:13:147-53. doi:10.1097/XEB.0000000000000054

32 Migliavaca CB, Stein C, Colpani V, Munn Z, Falavigna M, Prevalence Estimates Reviews - Systematic Review Methodology Group (PERSyst). Quality assessment of prevalence studies: a systematic review. J Clin Epidemiol 2020;127:59-68. doi:10.1016/j. jclinepi.2020.06.039 
33 Russell DW. UCLA Loneliness Scale (Version 3): reliability, validity, and factor structure. J Pers Assess 1996;66:20-40. doi:10.1207/ s15327752jpa6601_2

34 Gierveld JDJ, Tilburg TV. A 6-item scale for overall, emotional, and social loneliness: confirmatory tests on survey data. Res Aging 2006;28:582-98. doi:10.1177/0164027506289723

35 Penning MJ, Liu G, Chou PHB. Measuring loneliness among middle-aged and older adults: the UCLA and de Jong Gierveld Loneliness Scales. Soc Indic Res 2014:118:1147-66. doi:10.1007/s11205-013-0461-1

36 Hughes ME, Waite LJ, Hawkley LC, Cacioppo JT. A short scale for measuring loneliness in large surveys: results from two population-based studies. Res Aging 2004;26:655-72. doi:10.1177/0164027504268574

37 Martin G. Measuring loneliness: guidance for use of the national indicators on surveys. Office for National Statistics, 2018

38 Russell D. The measurement of loneliness. In: Peplau L, Perlman D, eds. Loneliness: A Sourcebook of Current Theory, Research and Theory. John Wiley \& Sons, 1982: 81-104.

39 Nicolaisen M, Thorsen K. Who are lonely? Loneliness in different age groups (18-81 years old), using two measures of loneliness. Int J Aging Hum Dev 2014;78:229-57. doi:10.2190/AG.78.3.b

40 Stijnen T, Hamza TH, Ozdemir P. Random effects meta-analysis of event outcome in the framework of the generalized linear mixed model with applications in sparse data. Stat Med 2010;29:3046-67. doi:10.1002/sim.4040

41 Fokkema T, De Jong Gierveld J, Dykstra PA. Cross-national differences in older adult loneliness. J Psychol 2012;146:201-28. doi:10.1080/ 00223980.2011 .631612

42 Hansen T, Slagsvold B. Late-life loneliness in 11 European countries: results from the Generations and Gender Survey. Soc Indic Res 2016;129:445-64. doi:10.1007/s11205-015-1111-6

43 Borges Migliavaca C, Stein C, Colpani V, Barker TH, Munn Z. Falavigna M, Prevalence Estimates Reviews - Systematic Review Methodology Group (PERSyst). How are systematic reviews of prevalence conducted? A methodological study. BMC Med Res Methodol 2020:20:96 doi:10.1186/s12874-020-00975-3

44 Barendregt JJ, Doi SA, Lee YY, Norman RE, Vos T. Meta-analysis of prevalence. J Epidemiol Community Health 2013;67:974-8 doi:10.1136/jech-2013-203104

45 Higgins JP, Thompson SG, Deeks JJ, Altman DG. Measuring inconsistency in meta-analyses. BMJ 2003;327:557-60. doi:10.1136/bmj.327.7414.557

46 Riley RD, Higgins JP, Deeks JJ. Interpretation of random effects metaanalyses. BM/ 2011;342:d549. doi:10.1136/bmj.d549

47 Rücker G, Schwarzer G, Carpenter JR, Schumacher M. Undue reliance on I(2) in assessing heterogeneity may mislead. BMC Med Res Methodol 2008;8:79. doi:10.1186/1471-2288-8-79

$48 \mathrm{Lim}$ MH, Eres R, Peck MC. The young Australian loneliness survey. Centre for Mental Health, Swinburne University of Technology, 2019.

49 Wilson C. Loneliness among Older Adults: A National Survey of Adults 45. AARP, 2010

50 Cigna. Loneliness and the Workplace: 2020 US Report. In: Ipsos, ed. Connecticut: Cigna, 2020. www.cigna.com/static/www-cignacom/docs/about-us/newsroom/studies-and-reports/combatting loneliness/cigna-2020-loneliness-report.pdf

51 Simpson IC, Dumitrache CG, Calet N. Mental health symptoms and verbal fluency in elderly people: Evidence from the Spanish longitudinal study of aging. Aging Ment Health 2019;23:670-9. doi:1 $0.1080 / 13607863.2018 .1448969$

52 Das A. Loneliness does (not) have cardiometabolic effects: A longitudinal study of older adults in two countries. Soc Sci Med 2019:223:104-12. doi:10.1016/j.socscimed 2018.10.021

53 Crowe CL, Domingue BW, Graf GH, et al. Associations of Loneliness and Social Isolation with Healthspan and Lifespan in the US Health and Retirement Study. / Gerontol A Biol Sci Med Sci 2021; published online first 5 September. doi:10.1093/gerona/glab128

54 Smith TO, Dainty JR, Williamson E, Martin KR. Association between musculoskeletal pain with social isolation and loneliness: analysis of the English Longitudinal Study of Ageing. Br J Pain 2019;13:82-90. doi: $10.1177 / 2049463718802868$

55 Victor CR, Pikhartova J. Lonely places or lonely people? Investigating the relationship between loneliness and place of residence. $B M C$ Public Health 2020;20:778. doi:10.1186/s12889-020-08703-8

56 Domènech-Abella J, Mundó J, Leonardi M, et al. The association between socioeconomic status and depression among older adults in Finland, Poland and Spain: A comparative cross-sectional study of distinct measures and pathways. J Affect Disord 2018;241:311-8. doi:10.1016/j.jad.2018.08.077

57 Baiden P, Kuuire VZ, Shrestha N, et al. Bullying victimization as a predictor of suicidal ideation and suicide attempt among senior high school students in Ghana: Results from the 2012 Ghana Global School-Based Health Survey. / Sch Violence 2019:18:300-17. doi:10 $.1080 / 15388220.2018 .1486200$
58 Vancampfort D, Ashdown-Franks G, Smith L, et al. Leisure-time sedentary behavior and loneliness among 148,045 adolescents aged 12-15 years from 52 low- and middle-income countries. I Affect Disord 2019;251:149-55. doi:10.1016/j.jad.2019.03.076

59 Pengpid S, Peltzer K. Single and multiple suicide attempts: prevalence and correlates in school-going adolescents in Liberia in 2017. Psychol Res Behav Manag 2020;13:1159-64. doi:10.2147/ PRBM.S277844

60 Amu H, Seidu A-A, Agbemavi W, et al. Loneliness and its associated risk factors among in-school adolescents in Tanzania: cross-sectional analyses of the Global School-based Health Survey data. Psychol Stud (Mysore) 2020;65:536-42. doi:10.1007/s12646-02000580-w

61 Seidu A-A, Dadzie LK, Ahinkorah BO. Is hunger associated with truancy among in-school adolescents in Tanzania? Evidence from the 2015 Global School-based Health Survey. J Public Health 2021;29:563-9. doi:10.1007/s10389-019-01165-2

62 Sauter SR, Kim LP, Jacobsen KH. Loneliness and friendlessness among adolescents in 25 countries in Latin America and the Caribbean. Child Adolesc Ment Health 2020;25:21-7. doi:10.1111/ camh. 12358

63 Elia C, Karamanos A, Dregan A, et al. Association of macro-level determinants with adolescent overweight and suicidal ideation with planning: A cross-sectional study of 21 Latin American and Caribbean Countries. PLoS Med 2020;17:e1003443. doi:10.1371/ journal.pmed.1003443

64 Antunes JT, Machado ÍE, Malta DC. Loneliness and associated factors among Brazilian adolescents: Results of national adolescent school-based health survey 2015. J Pediatr (Rio J) 2021;S00217557(21)00073-5. doi:10.1016/j.jped.2021.04.004

65 Pengpid S, Peltzer K. Prevalence and correlates of past 12-month suicide attempt among in-school adolescents in Guatemala. Psychol Res Behav Manag 2019:12:523-9. doi:10.2147/PRBM.S212648

66 Fox K, Gordon-Strachan G, Johnson A, Ashley D. Jamaican youth health status 2005. West Indian Med J 2009;58:533-8.

67 Pengpid S, Peltzer K. Trends in the prevalence of twenty health indicators among adolescents in United Arab Emirates: crosssectional national school surveys from 2005, 2010 and 2016. BMC Pediatr 2020;20:357. doi:10.1186/s12887-020-02252-0

68 Dendup T, Putra IGNE, Dorii T, et al. Correlates of sedentary behaviour among Bhutanese adolescents: Findings from the 2016 Global School-based Health Survey. Child Youth Serv Rev 2020;119:105520. doi:10.1016/j.childyouth.2020.105520

69 Pandey AR, Bista B, Dhungana RR, Aryal KK, Chalise B, Dhimal M. Factors associated with suicidal ideation and suicidal attempts among adolescent students in Nepal: Findings from Global Schoolbased Students Health Survey. PLoS One 2019;14:e0210383. doi:10.1371/journal.pone.0210383

70 Khan MMA, Rahman MM, Islam MR, Karim M, Hasan M, Jesmin SS Suicidal behavior among school-going adolescents in Bangladesh: findings of the global school-based student health survey. Soc Psychiatry Psychiatr Epidemiol 2020;55:1491-502. doi:10.1007/ s00127-020-01867-z

71 Pengpid S, Peltzer K. Suicide attempt and associated factors among adolescents in five Southeast Asian countries in 2015. Crisis 2020:41:296-303. doi:10.1027/0227-5910/a000642

72 Tan L, Ganapathy SS, Sooryanarayana R, et al. Bullying victimization among school-going adolescents in Malaysia: prevalence and associated factors. Asia Pac J Public Health 2019;31(suppl):18S-29S. doi:10.1177/1010539519870665

73 Shahedifar N, Shaikh MA, Oporia F, Wilson ML. Global School-based Student Health Survey reveals correlates of suicidal behaviors in Brunei Darussalam: a nationwide cross-sectional study. J Inj Violence Res 2020;12(Suppl 1):15.

74 Yang K, Victor C. Age and loneliness in 25 European nations. Ageing Soc 2011;31:1368-88. doi:10.1017/S0144686X1000139X

75 Victor CR, Yang K. The prevalence of loneliness among adults: a case study of the United Kingdom. J Psychol 2012;146:85-104. doi:10.10 80/00223980.2011.613875

76 Refaeli T, Achdut N. Perceived poverty, perceived income adequacy and loneliness in Israeli young adults: Are social capital and neighbourhood capital resilience factors?Health Soc Care Community 2020. doi:10.1111/hsc.13177

77 Stickley A, Koyanagi A, Roberts B, et al. Loneliness: its correlates and association with health behaviours and outcomes in nine countries of the former Soviet Union. PLoS One 2013;8:e67978. doi:10.1371/ journal.pone.0067978

78 Victor CR, Scambler SJ, Bowling A, et al. The prevalence of, and risk factors for, loneliness in later life: a survey of older people in Great Britain. Ageing Soc 2005;25:357-75. doi:10.1017/ S0144686X04003332

79 Sundström G, Fransson E, Malmberg B, Davey A. Loneliness among older Europeans. Eur J Ageing 2009;6:267-75. doi:10.1007/ s10433-009-0134-8 
80 Warton DI, Hui FK. The arcsine is asinine: the analysis of proportions in ecology. Ecology 2011:92:3-10. doi:10.1890/10-0340.1

81 Madsen KR, Holstein BE, Damsgaard MT, Rayce SB, Jespersen LN, Due P. Trends in social inequality in loneliness among adolescents 1991-2014. J Public Health (Oxf) 2019;41:e133-40. doi:10.1093/ pubmed/fdy133

82 Myhr A, Anthun KS, Lillefjell M, Sund ER. Trends in socioeconomic inequalities in Norwegian adolescents' mental health from 2014 to 2018: A repeated cross-sectional study. Front Psychol 2020;11:1472. doi:10.3389/fpsyg.2020.01472

83 Dahlberg L, Agahi N, Lennartsson C. Lonelier than ever? Loneliness of older people over two decades. Arch Gerontol Geriatr 2018;75:96103. doi:10.1016/j.archger.2017.11.004

84 Prohaska T, Burholt V, Burns A, et al. Consensus statement: loneliness in older adults, the 21st century social determinant of health? BMJ Open 2020;10:e034967. doi:10.1136/ bmjopen-2019-034967

85 Sha'ked A, Rokach A. Addressing Loneliness: Coping, Prevention and Clinical Interventions. Routledge, 2015. doi:10.4324/9781315774374

$86 \mathrm{Lim} \mathrm{M.} \mathrm{Australian} \mathrm{loneliness} \mathrm{report.} \mathrm{Swineburn} \mathrm{University} \mathrm{of}$ Technology, 2018.

87 Yang K. Loneliness: A Social Problem. Routledge, 2019. doi:10.4324/9781315148410

88 Saltkjel T, Dahl E, van der Wel KA. Health related social exclusion in Europe: a multilevel study of the role of welfare generosity. Int J Equity Health 2013;12:81. doi:10.1186/1475-9276-12-81

89 Pinquart M, Sorensen S. Influences on loneliness in older adults: a meta-analysis. Basic Appl Soc Psych 2001;23:245-66. doi:10.1207/ S15324834BASP2304_2

90 Petrov IC. The elderly in a period of transition: health, personality, and social aspects of adaptation. Ann N Y Acad Sci 2007;1114:300-9. doi:10.1196/annals.1396.041.
91 Coombs B. Loneliness is on the rise and younger workers and social media users feel it most, Cigna survey finds: CNBC; 2020. www.cnbc. com/2020/01/23/loneliness-is-rising-younger-workers-and-socialmedia-users-feel-it-most.html.

92 Beaton C. The 2 reasons why so many people are becoming lonelier Psychology Today; 2017. www.psychologytoday.com/au/blog/ the-gen-y-guide/201702/the-2-reasons-why-so-many-people-arebecoming-lonelier.

93 Sayin Kasar K, Karaman E. Life in lockdown: Social isolation, loneliness and quality of life in the elderly during the COVID-19 pandemic: A scoping review. Geriatr Nurs 2021;42:1222-9. doi:10.1016/j.gerinurse.2021.03.010

94 Pai N, Vella S-L. COVID-19 and loneliness: A rapid systematic review. Aust N Z J Psychiatry 2021;55:1144-56. doi:10.1177/00048674211031489

95 Uysal-Bozkir Ö, Parlevliet JL, de Rooii SE. Insufficient crosscultural adaptations and psychometric properties for many translated health assessment scales: a systematic review. J Clin Epidemiol 2013;66:608-18. doi:10.1016/j.jclinepi.2012.12.004

96 Chawla K, Kunonga TP, Stow D, Barker R, Craig D, Hanratty B. Prevalence of loneliness amongst older people in highincome countries: A systematic review and meta-analysis. PLoS One 2021;16:e0255088. doi:10.1371/journal.pone.0255088

97 Barreto M, Victor C, Hammond C, et al. Loneliness around the world: age, gender, and cultural differences in loneliness. Pers Individ Dif 2020;110066 doi:10.1016/i.paid.2020.110066.

98 Richardson M, Garner P, Donegan S. Interpretation of subgroup analyses in systematic reviews: a tutorial. Clin Epidemiol Glob Health 2019;7:192-8. doi:10.1016/j.cegh.2018.05.005

Supplementary information: Tables S1-S10 and figures S1-S10 